\title{
Requirements Elicitation Technique Selection: A Five Factors Approach
}

\author{
Mona Batra, Archana Bhatnagar
}

\begin{abstract}
Requirements Engineering phase is well recognized as a root of Software Development Life Cycle (SDLC) by research community. Requirements are elucidated through requirements elicitation methods conceded by requirement analyst. Requirements elicitation phase is planned and strategized to get complete acquaintance about user's requirements and expectations. Current software industries having massive necessity to help requirements analyst in requirements elicitation process to carry out precise manner. Correct and refined requirements lead to successful software projects. Vague and incorrect requirements possibly will result in the defective software project. For successful software development, it is vital to recognize precise and accurate requirements for the software project. The progression of information technology has presented various requirements elicitation techniques and therefore analysts are provided with various likely options. Generally, the analyst selects elicitation technique according to company practice or their individual knowledge and skills. It is undefined on the selection of best elicitation techniques for certain situations under particular constraints and circumstances. Several guidelines do exist in literature for technique selection but most technique are theoretical rather than practical.

In this research paper, deep knowledge of principal elicitation techniques is explained. After that a five facets model is proposed to select elicitation technique in which major aspects are project characteristics, software development process categories, organizational characteristics, stakeholder characteristics and analyst characteristics. We also demonstrate the suitability of the proposed framework via case studies and verified how the model uses relative knowledge of problem domain to select appropriate requirements elicitation technique for the software under construction.
\end{abstract}

Index Terms: Software Development Life Cycle, Software Engineering, Requirements Engineering, Requirements Elicitation, Research Framework, Techniques Selection.

\section{INTRODUCTION}

In the existing expanding information technology trends, industries endurance depends on the excellence of the software products delivered to customer. Software Engineering Body of Knowledge (SWEBOK) [1] define software development process as a blend of Requirements gathering, requirements analysis, designing, software architecture, implementation and maintenance. Large variety of tasks accomplished to grasp the requirements are acknowledged as Requirements Engineering [5]. It encompasses discovery of goals, requirements, potential viewpoints of stakeholders and communicate them to the

Revised Manuscript Received on April 19, 2019.

Mona Batra, ${ }^{1}$ Research Scholar, Department of Computer Science and Engineering, Birla Institute of Technology, Mesra, Ranchi, Jaipur Campus, Rajasthan, India.(Email id: monabatra89@gmail)

Archana Bhatnagar, Asst. Professor, Department of Computer Science and Engineering, Birla Institute of Technology, Mesra, Ranchi, Jaipur Campus, Rajasthan, India.(Email id: abhatnagar@bitmesra.ac.in) developers [6]. Requirements describe the functional and non-functional facet of software system, all facilities it offers and the boundary conditions on its operativeenvironment [3]. This phase of software development life cycle supports requirements analyst to grasp the actual need of software system and build an economic system [4].

Various researchers and practitioners describe different facets of Requirements Engineering (RE) process. According to SWEBOK [1] requirements engineering activities involve Requirements Elicitation, Analysis of requirements, Requirements Specification, Requirements Verification and Management. Pohl's define following steps in requirements modelling: Requirements Elicitation, Negotiation, Specification of requirements, Documentation and Requirements Verification/Validation [7]. Sommerville's requirements model comprised of Requirements Acquisition, Specification, Validation and Documentation of requirements [3]. Wiegers's RE model [8] splits whole RE activities into two fragments. First is Requirements Development and second is Requirements Management. Requirements Development activity consists of requirements elicitation, Analysis, Specification and Verification. Proper understanding of each requirements engineering process model and techniques are essential for effective software development [9]. Efforts and cost can be reduced by implementing the security aspect right from the beginning i.e. from the requirement phase itself [10].

Our work emphases on software requirements elicitation. Requirements elicitation phase is the initial and the utmost vital phase in requirements engineering process [2]. It is concerned with gathering of requirements for the software under creation. Bohem [15] defines requirements elicitation is the prime stage in requirements engineering process if not done properly leads to deprived quality of products, missing deadlines and high product costs. Loucopoulos et al. describe requirements elicitation as the practice to findng all appropriate facts to develop a structure of a problem related to particular domain [13]. Borland define requirements elicitation as the facility to work collectively with all stakeholders to determine product needs, vision and goals of proposed project [14]. According to Mulla et al. [2] requirements elicitation process consists of following phases: (1) Identification of requirements sources (2) Accumulate the wish list for individual corresponding part (3) Documentation and refinement of the wish list (4) Integrate the wish lists of all other stakeholders and (5) 
Identify the non-functional requirements. Bell et al. [12] observed in their study that requirements for system development would not rise spontaneously but they essentially engineered and need constant modification as well as evaluations.

Comprehensive and organized requirements can make software projects more consistent. This is significantly influenced by the techniques used during requirements elicitation process [3]. Any application development is essentially required incorporation of good requirements elicitation practices. There are number of techniques exists in literature like interview, brainstorming, protocol analysis, survey, observation analysis laddering etc. [17][18][19][20][21][22][23][24][25]. Requirements elicitation techniques selection for a certain software project domain is a challenging task. A variety of components influence the selection process. There is not a single flawless elicitation technique that can satisfy each and every condition, as there is no agreement among software experts on the selection of finest elicitation technique to elicit information. Deep literature review conducted by authors [11] suggested to incorporate application specific elicitation technique for successful software development and management.

To overcome this problem, we are proposing an approach that focuses on the important factors that affect requirements elicitation process. We have exposed both the present theory and the results of experimental research to design the approach. We have also used our own experience and expertise for designing this framework. The paper aims to provide a guide for selecting the correct requirements elicitation techniques based on the above factors. The attributes of all the factors are based on from literature surveys, case studies and in-depth discussion with software experts.

The paper is formed in four sections. Next section presented the brief information about the requirement elicitation techniques along with strength and weaknesses. Section III, proposed approach for selecting requirements elicitation technique. Working of the proposed framework is explained with the support of case studies in section IV. At the end conclusion is presented in section $\mathrm{V}$.

\section{REQUIREMENTS ELICITATION TECHNIQUES}

Academicians, experts and practitioners are working in the area of requirements engineering. They mainly focused in the direction of improving the complex requirements elicitation process with the progress of various techniques, practices and tools. Quite a lot of these techniques have been occupied and adopted from other fields like social sciences but only limited number of techniques have been selected for requirements elicitation [16]. This segment describes the classification of requirements elicitation methods. Requirements development is done thorough numerous interactions between stakeholders and requirements analysts [17]. According to the means of communication requirements elicitation techniques are categorized into four types: Conversational, Collaborative, Analytic, and Contextual techniques [17][18][19][20][21][22][23][24][25]. Each category signifies a particular interaction model between stakeholders and requirements analyst and also depicts the nature of a method.

This section exemplifies basic details of requirements elicitation techniques along with their strengths and weaknesses. Requirements elicitation techniques can be categorized into four types [26]:

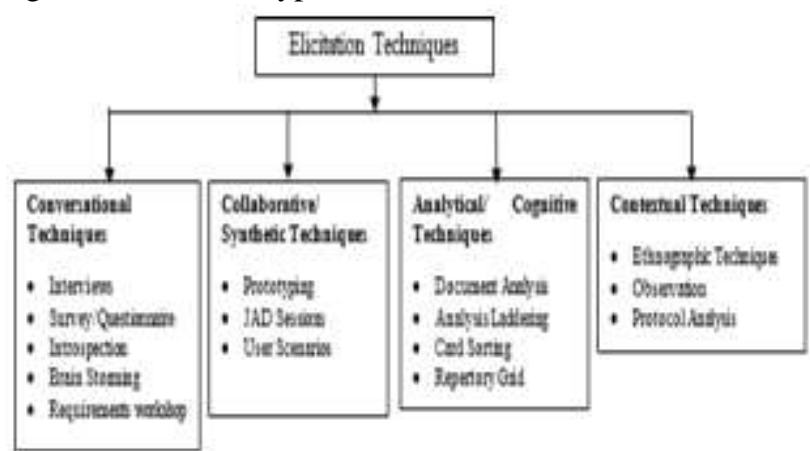

Figure 1: Requirements Elicitation Techniques

\section{A. Conversational (Traditional) Techniques:}

The conversational method also known as traditional methods or verbal methods [1] typically describe the oral communication among two or more people. Conversation is an ordinary means to express requirements and ideas, via asking questions and replying to the particular questions. Its main focus is to understand problem in details and gather requirements for generic products. Details of traditional techniques are described in the table below: 
Table 1: Traditional Requirements Elicitation Techniques

\begin{tabular}{|c|c|c|c|}
\hline Technique & Description & Strength & Weakness \\
\hline Interview & $\begin{array}{l}\text { The requirements analyst } \\
\text { queationed to different } \\
\text { stakeholders, to produce detail } \\
\text { information about objectives of } \\
\text { present work and related problems } \\
\text { in a software project. }\end{array}$ & $\begin{array}{l}\text { - Able to gain } \\
\text { complete view of the } \\
\text { system. } \\
\text { - Detailed and } \\
\text { informative data is } \\
\text { collected. }\end{array}$ & $\begin{array}{l}\text { - Mostly imprecise } \\
\text { and large data is } \\
\text { collected. } \\
\text { - If not properly } \\
\text { planned, difficult to } \\
\text { gain particular } \\
\text { information. }\end{array}$ \\
\hline Survey/Questionnaire & $\begin{array}{l}\text { Swrveys / Questionnairss are } \\
\text { basically used to collect facts } \\
\text { anonymously from many people in } \\
\text { a short span of time [28]. }\end{array}$ & $\begin{array}{l}\text { - Cheap in cost. } \\
\text { - Performed in less } \\
\text { time. } \\
\text { - Gather huge amount } \\
\text { of dats from large } \\
\text { number of users. } \\
\text { - Quick analysis of } \\
\text { data. }\end{array}$ & $\begin{array}{l}\text { - Collected data can } \\
\text { be ambiguous. } \\
\text { - Complete view of } \\
\text { system not } \\
\text { possible. }\end{array}$ \\
\hline Introspection & $\begin{array}{l}\text { The introspection technique [23] } \\
\text { analyst develops requirements } \\
\text { based on its own perception about } \\
\text { users need from the system. } \\
\text { Introspection is only effective } \\
\text { when analyst not only having } \\
\text { expertise about domain knowledge } \\
\text { but also knowledgeable in the } \\
\text { business processes [31]. }\end{array}$ & $\begin{array}{l}\text { - Basis of other } \\
\text { elicitation } \\
\text { techniques. } \\
\text { - Zero cost required. }\end{array}$ & $\begin{array}{l}\text { - Analyst should be } \\
\text { expert in the } \\
\text { business process of } \\
\text { the system. }\end{array}$ \\
\hline $\begin{array}{l}\text { Requírements } \\
\text { Workshop }\end{array}$ & $\begin{array}{l}\text { In Work shop different types of } \\
\text { meeting is conducted with the } \\
\text { stakeholders to collect the } \\
\text { requirements for the project under } \\
\text { development. }\end{array}$ & $\begin{array}{l}\text { Provide } \\
\text { comprehensive set } \\
\text { of requirements. } \\
\text { Useful for } \\
\text { gathering large } \\
\text { and complex } \\
\text { requirements. }\end{array}$ & $\begin{array}{l}\text { - It is a costly } \\
\text { approach. } \\
\text { - Slow process. } \\
\text { Not useful for small } \\
\text { projects. }\end{array}$ \\
\hline Brain Storming & $\begin{array}{l}\text { Brainstorming is conducted as a } \\
\text { form of conference with six to ten } \\
\text { participants from different } \\
\text { background. Each member } \\
\text { presents great ideas for the } \\
\text { solution of problem. } \\
\text { Best idea is nominated by } \\
\text { members voting as a solution for } \\
\text { the problems [24]. }\end{array}$ & $\begin{array}{l}\text { Useful in producing } \\
\text { innovative ideas. }\end{array}$ & $\begin{array}{l}\text { Not suitable for } \\
\text { small group of } \\
\text { stakeholders with } \\
\text { dissimilar needs. }\end{array}$ \\
\hline
\end{tabular}

\section{B. Collaborative Techniques}

It is also called as Synthetic methods. The synthetic methods integrate various communication channels, and suggests models to demonstrate the characteristics and relationship of system. 
International Conference on Recents Advancements in Engineering and Technology (ICRAET-18) |15th and 16th March 2019|Siddhartha Institute of Technology \& Sciences, Telangana, India.

Table 2: Collaborative Requirements Elicitation Techniques

\begin{tabular}{|c|c|c|c|}
\hline Technique & Description & Strength & Weakness \\
\hline Prototyping & $\begin{array}{l}\text { In this initial visualization of the } \\
\text { system is created which often used to } \\
\text { confirm system requirement. } \\
\text { Stakeholders can recognize the real } \\
\text { requirements and work flow of actual } \\
\text { system. }\end{array}$ & $\begin{array}{l}\text { Beneficial in developing } \\
\text { new system. } \\
\text { Helps to understand } \\
\text { detailed knowledge of } \\
\text { requirements. }\end{array}$ & $\begin{array}{l}\text { Expensive in terms of } \\
\text { cost. } \\
\text { It may not create quickly } \\
\text { because of complexity of } \\
\text { system and technical } \\
\text { limitation. }\end{array}$ \\
\hline $\begin{array}{l}\text { JAD (Joint } \\
\text { Application } \\
\text { Development) } \\
\text { sessions }\end{array}$ & $\begin{array}{l}\text { JAD is a requirement methodology in } \\
\text { which stakeholders, subject matter } \\
\text { experts (SME), software architects and } \\
\text { developers attend intense offsite } \\
\text { meetings to work out on a system's } \\
\text { details and business problem [30]. }\end{array}$ & $\begin{array}{l}\text { Direct communication } \\
\text { with stakeholders. } \\
\text { Accommodate rapid } \\
\text { decisions and quickly } \\
\text { handles changes is } \\
\text { requirements. }\end{array}$ & $\begin{array}{l}\text { Analyst must be expert in } \\
\text { problem domain. }\end{array}$ \\
\hline User Scenarios & $\begin{array}{l}\text { Also called as use cases and represents } \\
\text { functional aspects of the system. It } \\
\text { should specify a sequence of } \\
\text { interactions between a system and an } \\
\text { external } \\
\text { Actor [20]. }\end{array}$ & $\begin{array}{l}\text { Set of requirements can } \\
\text { be gather in cheaper cost. }\end{array}$ & $\begin{array}{l}\text { Stakeholder's availability } \\
\text { is always required. }\end{array}$ \\
\hline
\end{tabular}

\section{Cognitive Techniques}

Cognitive techniques make use of present system documentation to capture requirements. It discovers expert's acquaintance of current system and obtain requirements from sequence of assumptions carried out for gather large information about problem domain.

Table 3: Cognitive Requirements Elicitation Techniques

\begin{tabular}{|c|c|c|c|}
\hline Technique & Description & Strength & Weakness \\
\hline $\begin{array}{l}\text { Document } \\
\text { Analysis }\end{array}$ & $\begin{array}{l}\text { - Document analysis is a technique that } \\
\text { uses existing document to collect } \\
\text { requirements of a current system. By } \\
\text { studying current documentation } \\
\text { significant information can be } \\
\text { identified [27]. }\end{array}$ & $\begin{array}{l}\text { It works efficiently to } \\
\text { capture domain } \\
\text { lnowledge where it is } \\
\text { hard to articulate and } \\
\text { understand. }\end{array}$ & - It consumes lot of time. \\
\hline $\begin{array}{l}\text { Analysis } \\
\text { Laddering }\end{array}$ & $\begin{array}{l}\text { In this method requirements are } \\
\text { gathered with the help of structure } \\
\text { interview. The set of questions are } \\
\text { arranged in hierarchical form. The } \\
\text { success factor of this approach is } \\
\text { dependent stakeholder's domain } \\
\text { lnowledge. }\end{array}$ & 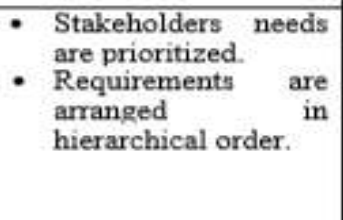 & $\begin{array}{l}\text { Requirements maintenance is } \\
\text { difficult particularly } \\
\text { accumulation and removal of } \\
\text { requirement. } \\
\text { Not suitable technique for } \\
\text { complex system having numeral } \\
\text { requirements. }\end{array}$ \\
\hline Card Sorting & $\begin{array}{l}\text { In this technique participants sort the } \\
\text { set of cards into a cluster where each } \\
\text { card is written with the explanation of } \\
\text { domain entities. } \\
\text { Card sorting helps the requirements } \\
\text { analyst to collect requirements closer } \\
\text { to the thinking of intended users. }\end{array}$ & $\begin{array}{l}\text { - Helps the } \\
\text { stakeholder to } \\
\text { recollect the domain } \\
\text { knowledge and } \\
\text { differentiate between } \\
\text { high level and low- } \\
\text { level problems. }\end{array}$ & $\begin{array}{l}\text { - Deep domain knowledge is } \\
\text { must. } \\
\text { - Complex cards might confuse } \\
\text { novice stakeholders. }\end{array}$ \\
\hline Repertory Grid & $\begin{array}{l}\text { Repertory grids [29] create a grid in the } \\
\text { form } \\
\text { of a matrix. Store the requirements by } \\
\text { asking stakeholders to develop } \\
\text { attributes } \\
\text { and assign values to a set of domain } \\
\text { units. } \\
\text { Helps to create dissimilarity between } \\
\text { different information domains. }\end{array}$ & $\begin{array}{l}\text { Ease to trace } \\
\text { requirement and able } \\
\text { to establish } \\
\text { interconnection } \\
\text { between domain } \\
\text { requirements. } \\
\text { - Gather in } \\
\text { characteristics ificient way. } \\
\text { efficion }\end{array}$ & $\begin{array}{l}\text { Not able to identify complex } \\
\text { requirements. }\end{array}$ \\
\hline
\end{tabular}




\section{Observational Techniques}

Observation methods gather information by surveil human actions at the atmosphere wherever software system is expected to be placed in case of new system or already located, in the case of present system.

Table 4: Collaborative Requirements Elicitation Techniques

\begin{tabular}{|c|c|c|c|}
\hline Technique & Description & Strength & Weakness \\
\hline $\begin{array}{l}\text { Ethnographic } \\
\text { Technique }\end{array}$ & $\begin{array}{l}\text { Ethnography is the process of } \\
\text { interrelating } \\
\text { with stakeholders of different } \\
\text { background to get knowledge of } \\
\text { political situation within organization. }\end{array}$ & $\begin{array}{l}\text { - Capture social } \\
\text { factors and } \\
\text { patterns for } \\
\text { identify } \\
\text { solution } \\
\text { - Gather quality } \\
\text { requirements } \\
\text { such as } \\
\text { usability and } \\
\text { efficiency. } \\
\text { Useful in complex } \\
\text { Software projects. }\end{array}$ & $\begin{array}{l}\text { - Does not suitable in cases wherever } \\
\text { peoples are highly assorted. } \\
\text { - Difficult to investigate social } \\
\text { requirement of communities } \\
\text { - It is a lengthy process so it is not } \\
\text { suitable when requirements } \\
\text { elicitation team having very short } \\
\text { span of time. }\end{array}$ \\
\hline Observation & $\begin{array}{l}\text { It is also known as social analysis. This } \\
\text { method collects user requirements by } \\
\text { investigating people performing their } \\
\text { normal work [19]. }\end{array}$ & $\begin{array}{l}\text { - Most trustworthy } \\
\text { technique } \\
\text { - Easy for analyst to } \\
\text { verify and validate } \\
\text { requirements. }\end{array}$ & $\begin{array}{l}\text { - It may result wrong requirements } \\
\text { if analyst not perform carefully. } \\
\text { - It is costly as it may include some } \\
\text { unwanted expenses like travel } \\
\text { expenses. }\end{array}$ \\
\hline $\begin{array}{l}\text { Protocol } \\
\text { Analysis }\end{array}$ & $\begin{array}{l}\text { - The stakeholders speak aloud while } \\
\text { performing the tasks and the analyst } \\
\text { records stakeholders' actions in the } \\
\text { form of video, audio or written notes. } \\
\text { Requirements analyst make use of these } \\
\text { recording to gather meaningful } \\
\text { requirements for designing any } \\
\text { application. }\end{array}$ & $\begin{array}{l}\text { - It is suitable to } \\
\text { determine what } \\
\text { stakeholders says } \\
\text { is what they do. }\end{array}$ & $\begin{array}{l}\text { - Analyst should have sound domain } \\
\text { knowledge. } \\
\text { - There might be chances of } \\
\text { misunderstanding among } \\
\text { stakeholders. } \\
\text {-Sometimes provide imprecise } \\
\text { requirement. } \\
\text { - Not suitable for large project. }\end{array}$ \\
\hline
\end{tabular}

\section{PROPOSED APPROACH FOR SELECTING REQUIREMENTS ELICITATION TECHNIQUE}

For the development of the framework, we have studied the facts of requirements elicitation techniques with respect to software project, software development process, organization culture, stakeholders' characteristics and analyst attributes with the help of research work of academicians, experience reports of software experts, project reports and experts' advices. The working of the framework can be explained as below:

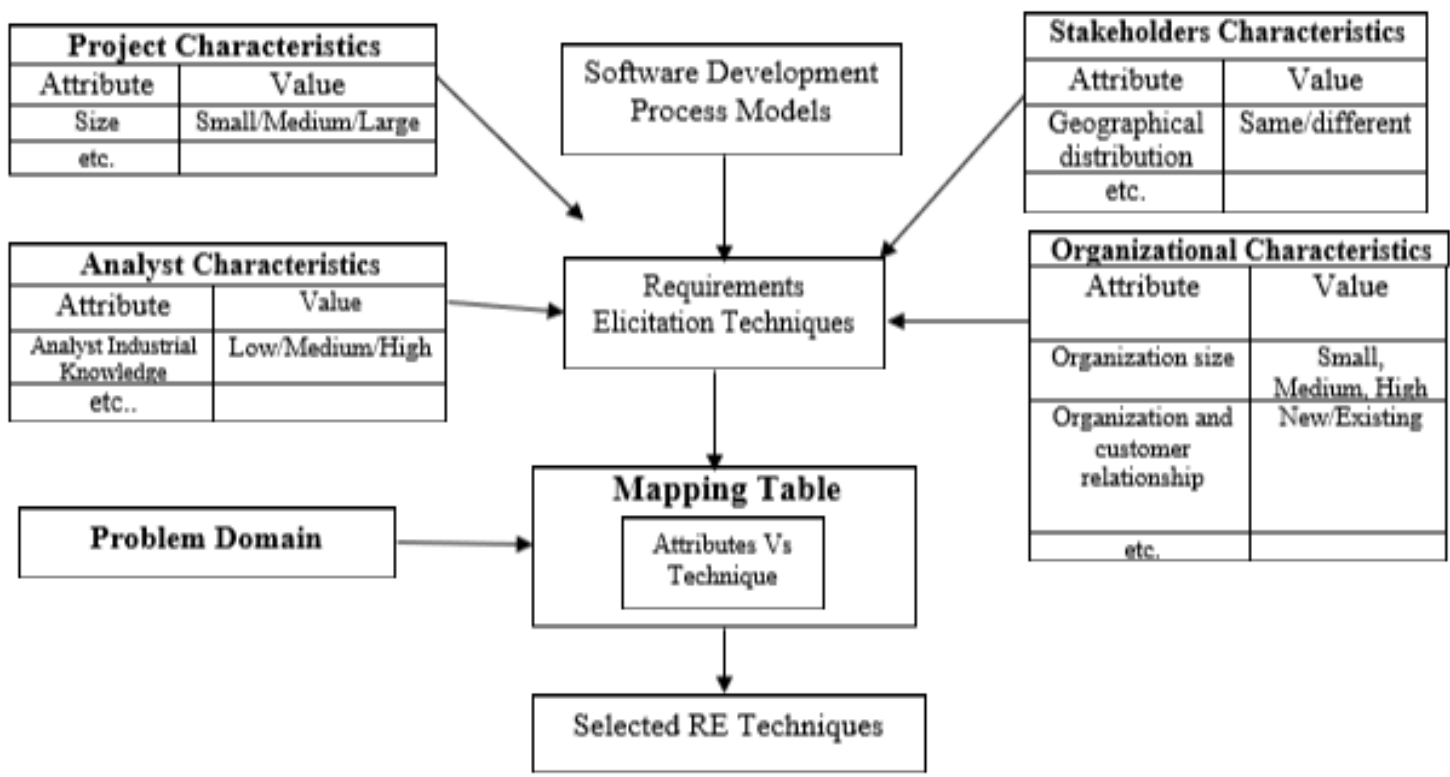

Figure 2: Proposed approach for selecting requirements elicitation technique 
International Conference on Recents Advancements in Engineering and Technology (ICRAET-18) |15th and 16th March 2019|Siddhartha Institute of Technology \& Sciences, Telangana, India.

1) We have identified several significant traits for each of the five factors that influence the selection process. The five factors are project, stakeholder, analyst, organization and software development process.

2) We have constructed an attribute table for all five factors. Each table having the attribute name and its value. Values are assigned according to literature work, real-life software project report and expert advice.

3) We construct a mapping table for each attribute of the above mentioned five factors and their association with the elicitation techniques. Mapping table act as a decision system to select of elicitation technique for a given problem domain.

4) Problem domain comprises of some known characteristics that comes from feasibility study before requirements elicitation process begins. Figure 1 depicted the proposed framework.

5) List of Attributes chosen for each factor table is listed below:

A. Project Characteristics
Project characteristics plays an important role for selecting requirements elicitation techniques. Ten project attributes have been considered for the analysis of each RE technique. The first attribute is Project Size and the values associated with this are Small, Medium, Large. The second attribute is Project Complexity and its associated values can be Low, Medium, High. Third attribute is Time Constraints and its associated value can be Low, Medium or High. Fourth attribute to consider is Cost Constraints and it can be Low, Medium, High. Fifth attribute is Project Category and project can be Organic, Semidetached, Embedded. Sixth attribute is Project Status and project can be existing or new. Seventh attribute is Project Scope that can be either Public or Private. Eighth attribute is Requirements Volatility that describe change is number of requirements and it can be Small, Medium or Large. Ninth attribute is Project Safety that can be Low, Medium or High. Last and tenth attribute is User involvement it can be Low, Medium or High. Each value can be ranged according to Probability. In statistics, probability lies between 0 to 1 . Graph 1 depicted the association between Requirements elicitation techniques and Project Characteristics.

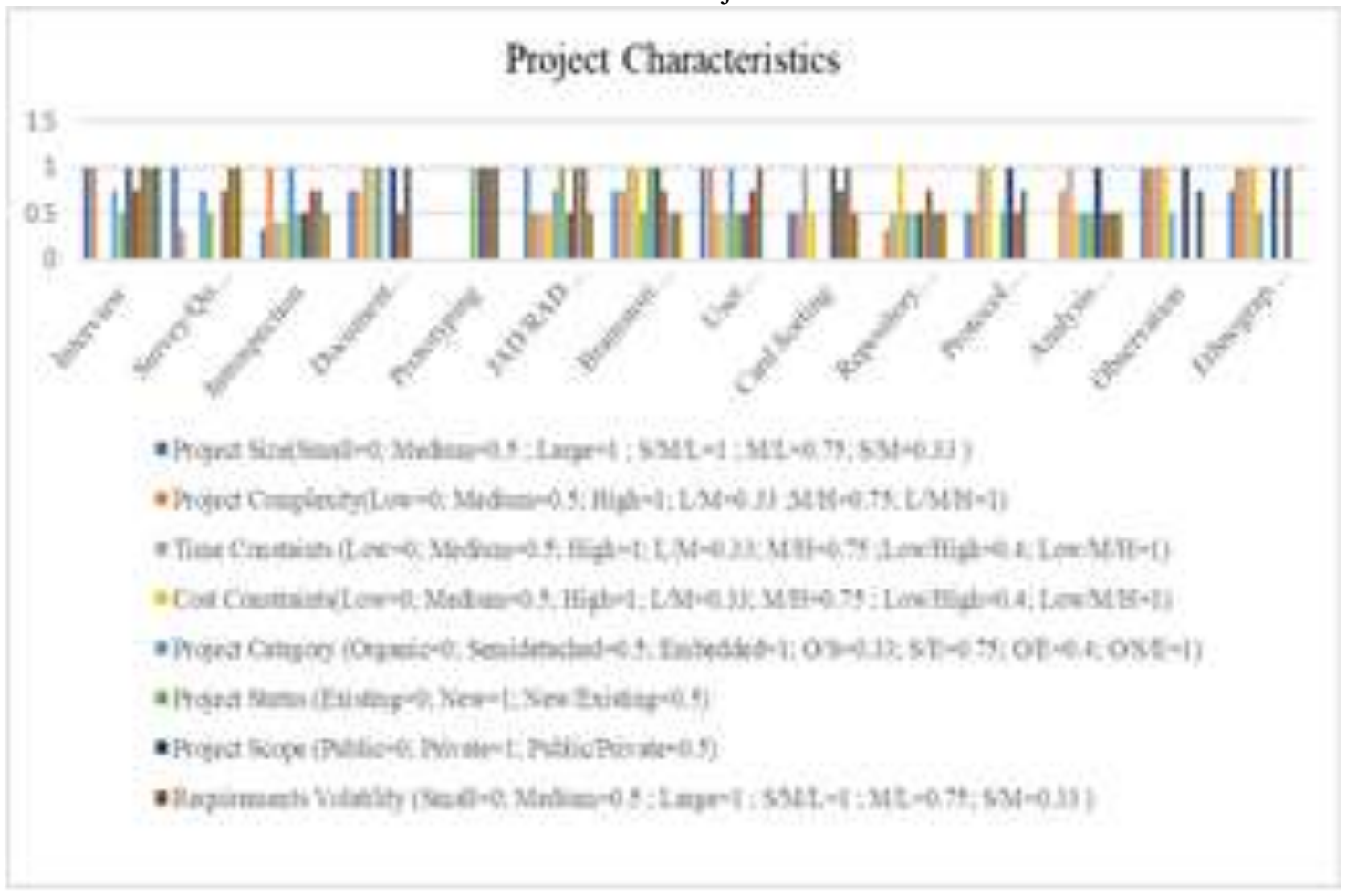

Graph 1. Elicitation Techniques Vs Project Characteristics

\section{B. Organization Characteristics}

Organizational characteristics reflect significant role while selecting requirements elicitation techniques. Organizational features that affects overall working of software development. The Organization attributes that has been considered for the analysis of each elicitatiom technique are organization size (Small, Medium; Large. Organization and customer relationship (New or existing), Impact of organizational culture (Yes, No). Graph 1 depicted the association between Requirements elicitation techniques and Organizational Characteristics. 


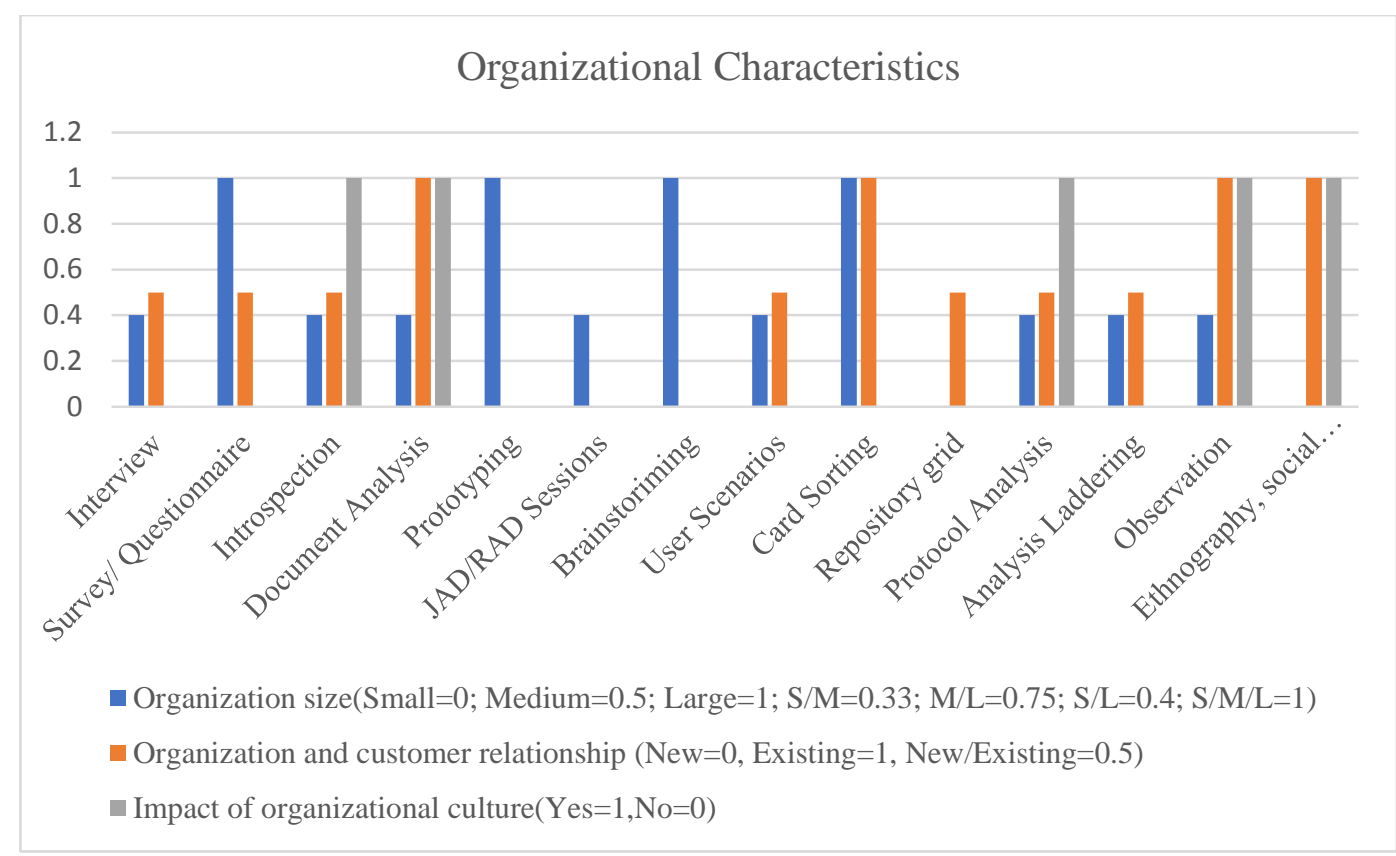

Graph 2. Elicitation Techniques Vs Organizational Characteristics

\section{Software Development Process Model Characteristics}

There are lots of software development process model exist in literature. The most popular software process models are: Waterfall oftware Development Model, Spiral Model, Prototype Model, Rapid Application Development process model, Extreme Programming (XP), Scrum.

The software processes also impacted on the selection of elicitation techniques. Below, Graph 3 depicts the relation between process model and elicitation techniques. Applicability is ranged between 0 to 1 . If a specific process model scores 1 for any elicitation technique that means that technique gives the accurate requirements with respect to specific process model. If it scores 0 that that requirements elicitation technique gives ambiguous results. Moderate results between 0 to 1 .

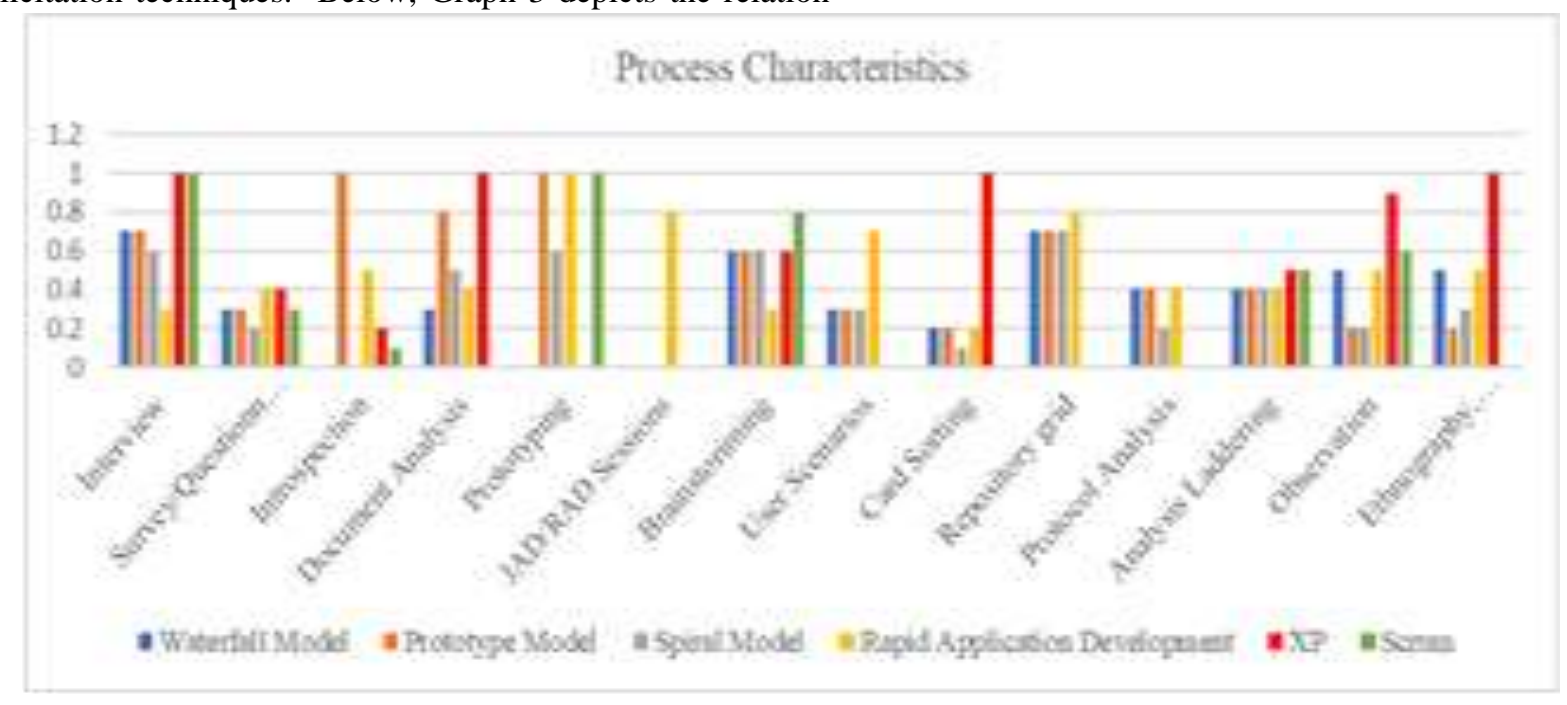

\section{Graph 3. Elicitation Techniques Vs Software Process Characteristics}

\section{Stakeholder Characteristics}

Stakeholder possessed most important role in developing effective software. Attributes chosen for the analysis of stakeholder characteristics are: Geographical distribution (same location, different location), number of stakeholder (single, group), Stakeholder Availability (Yes, No),
Stakeholder Experienced (Fresher, Experienced), Stakeholder Knowledge (Low, Medium, High), Stakeholder Expressiveness (Low, Medium, High). The Graph 4 depicts the relationship between stakeholder characteristics and requirements elicitation techniques. 


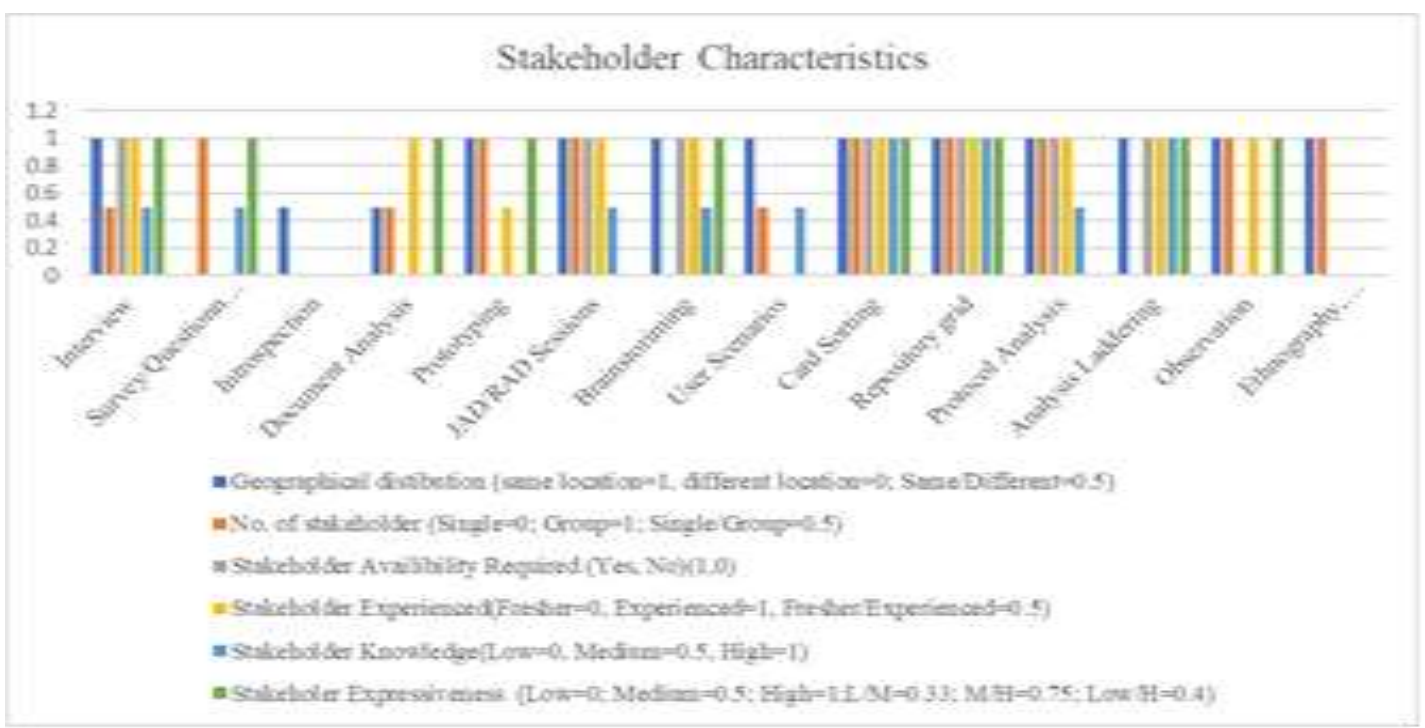

\section{Graph 3. Elicitation Techniques Vs Stakeholder Characteristics}

\section{E. Analyst Characteristics}

Analyst is a person who understand the needs of stakeholders and communicate them to developer. There attributes play a significant role in requirements elicitation. The attribute considered for the framework are

Analyst's Industrial Knowledge (Low, Medium, High), Analyst Experience (Fresher, Experienced), Problem domain knowledge (Low, Medium, High). The Graph 5 depicts the relationship between analyst Characteristics and requirements elicitation techniques.

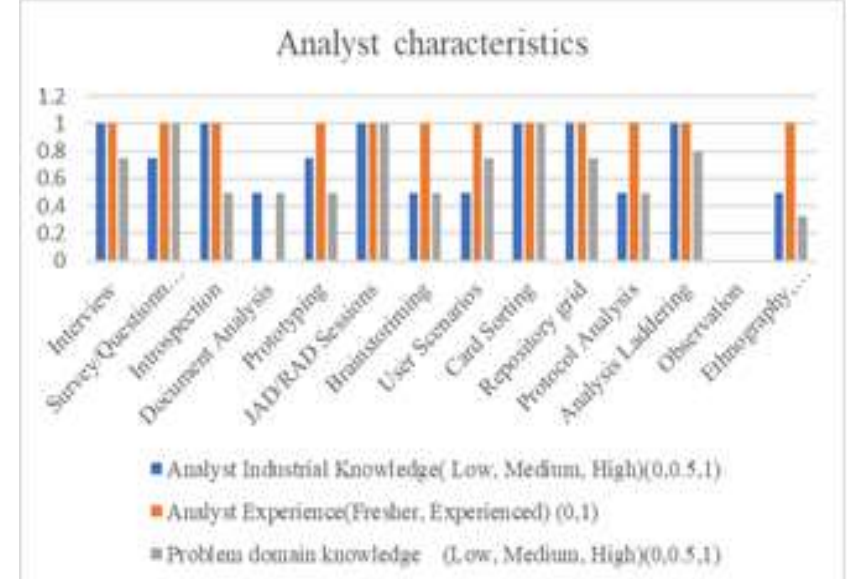

\section{Graph 3. Elicitation Techniques Vs Analyst Characteristics}

\section{CASE STUDIES FOR EXAMINING THE WORKING OF FRAMEWORK}

The section below discusses about the suitability of proposed framework using three case studies. We have applied the approach to Online Examination System, Port Scheduling System and E-Governance Lok Mitra project. Each of the case studies has been explained below:

\section{A.Online Examination System}

It is a software resolution that facilitates any industry or institute to arrange, conduct and manage online examination. It permits various peoples to give the exam and presents the results at the end of the exam. System administrator can create, alter and remove questions from test papers. End-uses can register themselves, login and perform the test with his own specific id and can also see the results as well. It is a cost-effective, less time consuming and most popular means of mass- evaluation system.

Users of online examination system can be categories into two kinds: Administrator and Examinee. This project has following known characteristics.

- Project Characteristics: project size- is applicable for educational institute (small, medium), Project Complexity should be medium, time and cost constraints would be medium, Project Scope can be public or private, project safety will be high and User involvement- low.

- $\quad$ Process Characteristics: Waterfall Model

- Organizational Characteristics: Organizational Size- Organization can be small/ medium as institute and Impact of organizational culture- No

- Stakeholder Characteristics: Geographical distribution- Same, No. of stakeholder- Group, Stakeholder Availability Required- No, Stakeholder ExperiencedFresher

- Analyst Characteristics: Analyst Industrial Knowledge: High, Problem domain knowledge: high

Results: when we analyzed known attributes with mapping table, we identified Interview, brainstorming, repertory grid, ethnography, Introspection, JAD, Analysis Laddering are the techniques which gives effective results.

\section{B. Port Scheduling System}

The objective of the project "Port Scheduling System" is to schedule a container terminal with maximum of 1 million TEU (20-foot equivalent unit) throughput each year. The terminal essentially handles small sized cargo also. The project encompasses an extremely interactive interface and a high degree of computerization of the control functions and arrangement of port.

This project has following known characteristics.

- Project Characteristics: Project size: Medium,

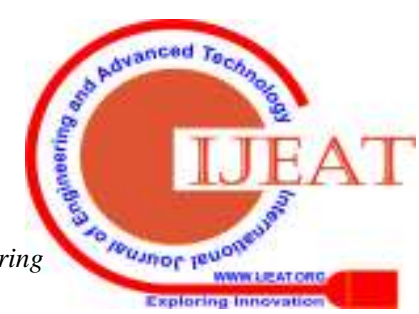


Project complexity: Medium, Cost Constraints: High, Project category: Semi-detached, Requirements volatility: Low, Project Type: New, Project safety: High.

- Organizational Characteristics: Organization size: Large, Organization and customer relationship: New

- Stakeholder Characteristics: No. of stakeholderSingle.

- Analyst Characteristics: Analyst Industrial Knowledge: High, Problem domain knowledge: High

Results: when we analyzed known attributes with mapping table, we identified Interview, Ethnography, JAD, Card sorting are best techniques which produces effective results.

\section{Lok Mitra}

It is the first electronic service in the state of Rajasthan. Its purpose is to arrange Information Technology for the assistance of the common people. With this, people get wellorganized effective services through IT driven interfaces. It is an e-governance project in which a single server is connected to different Departmental servers via Devoted Leased Line \& Dial-up Network with various electroniccounters, which can manage all related services. It also provided facilities of making payments with the help of Internet by means of Credit Card.

Lok Mitra majorly having types of users- Administrator and Citizens. Following listed some known characteristics:

- $\quad$ Project Characteristics: Project size- Large, project Complexity should be high, time and cost constraints would be medium, Project Scope can be public, Project Statusexisting, project safety will be high and User involvementhigh.

- Organizational Characteristics: Organizational Size- Organization can be large and Impact of organizational culture- existing.

- Stakeholder Characteristics: Geographical distribution- Same, No. of Stakeholder- Group, Stakeholder Availability Required- Yes, Stakeholder ExperiencedFresher

- Analyst Characteristics: Analyst Industrial Knowledge: High, Problem domain knowledge: Medium

Results: when we analyzed known attributes with mapping table, we identified card sorting, survey, Interview, Brainstorming, introspection and analysis laddering are the techniques which gives effective results.

\section{CONCLUSION}

In this paper, we have presented a meaningful deep insight into various types of requirements elicitation techniques along with their strengths and weaknesses. Requirements Elicitation process is extremely affected by stakeholder characteristics, software project attributes, software process model involved and organizational attributes. Elicitation technique has possessed specific set of unique features that is focused to related application. In this paper, we outline a way to elect a set of requirements elicitation methods for getting the best results in requirement elicitation process. A mapping table is created for each factor with respect to requirements elicitation techniques. Problem domain is a known attribute for the
- Process characteristics: Waterfall Model

problem under construction. It acts as an input for mapping table and results will be the set of effective elicitation techniques that gives optimal results for gathering requirements. The requirements elicitation is still one of the major challenging area in software development. By examining problem domain with respect to above mentioned five factors helps the effective way to make an optimal choice of picking requirements elicitation techniques. Future work is to identify other factors and incorporate it in this framework for making it better way to select best requirement elicitation techniques for particular circumstances.

\section{REFERENCES:}

1. Bourque, P. and Fairley, R.E. "Guide to the software engineering body of knowledge", Version 3.0. IEEE Computer Society. Retrieved April 2, 2019, from www.swebok.org,.https://www.computer.org/education/b odies-of-knowledge/software-engineering

2. Mulla, N. and Girase, S. "A new approach to requirement elicitation based on stakeholder recommendation and collaborative filtering". International Journal of Software Engineering \& Applications (IJSEA), 3(3), 51-61, 2012.

3. Sommerville, I. Software engineering (9th ed.). Boston: AddisonWesley,(2011)..https://inspirit.net.in/books/acad emic/Ian\%20Sommerville\%20Software\%20Engineering, \%209th\%20Edition\%20\%20\%20\%202011.pdf

4. Batra, Mona and Bhatnagar Dr. Archana, "Requirements Prioritization: A Review", International Journal of Advanced Research in Science, Engineering and Technology, Vol. 3, Issue 11, November 2016 http://www.ijarset.com/upload/2016/november/6_IJARS ET monabatra.pdf

5. Pressman, R. Software engineering: a practitioner's approach (7th ed.). New York: McGraw-Hill higher education,2010.http://dinus.ac.id/repository/docs/ajar/RP L7th_ed_software_engineering_a_practitioners_approach by_roger_s._pressman_.pdf

6. Nuseibeh, B.; and Easterbrook, S. Requirements engineering: a roadmap. Proceedings of the 22nd International Conference on Software Engineering ICSE'00. Limerick, Ireland, 4-11, 2000 https://www.cs.toronto.edu/ sme/papers/2000/ICSE2000 .pdf

7. Pohl, K. Requirements engineering: Fundamentals, principles, and techniques. Springer. Berlin, Germany, 2010.

http://elearn.dsum.org/pluginfile.php/2357/mod_resource /content/0/_Klaus_Pohl_Chris_Rupp_Requirements_Eng ineering b-\%20\%281\%29.pdf

8. Wiegers, K. E. (1999). Software requirements. Microsoft Press.https://dl.acm.org/citation.cfm?id=519610

9. Batra, Mona and Bhatnagar Dr. Archana "A Comparative Study of Requirements Engineering Process Model" International Journal of Advanced Research in Computer Science, Volume 8, No. 3, March - April 2017.https://www.academia.edu/35642649/A_Comparati ve_Study_of_Requirements_Engineering_Process_Mode

10. Batra, Mona and Pandey S.K., "Security Testing in Requirements Phase of SDLC", International Journal of Computer Applications (0975 - 8887) Volume 68- No.9, April 2013. 
11. Batra, Mona and Bhatnagar Dr. Archana, "Descriptive Literature Review of Requirements Engineering Models", International Journal of Advanced Research in Computer Science and Software Engineering, Volume 5, Issue2,February2015.http://ijarcsse.com/Before August 2017/docs/papers/Volume_5/2_February2015/V5I20331.pdf

12. Bell T.E. and Thayer T.A., "Software requirements: are they really a problem", 2nd International Conference on Software engineering, pp 61-68, IEEE Computer Society Press, 1976.https://pdfs.semanticscholar.org/a50d/8f564d 063e526e94114875220440f64d8666.pdf

13. Loucopoulos, P. and Karakostas, V. System requirements Engineering. New York: McGraw-Hill, 1995. https://dl.acm.org/citation.cfm?id=545779

14. Borland Software Corporation, "Mitigating risk with effective requirements engineering how to improve decision-making and opportunity through effective requirements engineering". Part two in a series about understanding and managing risk.

15. Bohem, B.R.W. (1981). Software engineering economics. New Jersey: Prentice - Hall.

16. Coulin, C., Zowghi, D., "Requirements Elicitation for Complex Systems: Theory and Practice, in Requirements Engineering for Socio-Technical Systems", 20.0

17. Zhang Zheying, "Effective Requirements Development A Comparison of Requirements Elicitation techniques", SQM2007-International Conference on Strangeness in Quark Matter. http://citeseerx.ist.psu.edu/viewdoc/download?doi=10.1. $1.135 .185 \& \mathrm{rep}=\mathrm{rep} 1 \&$ type $=$ pdf

18. Lloyd W. J., Rosson M. B. and Arthur J. D., "Effectiveness of elicitation techniques in distributed requirements engineering", Proceedings of the IEEE International Conference on Requirements Engineering, 2002, $\mathrm{pp}$.

311-318. https://doi.org/10.1109/ICRE.2002.1048544

19. Gunda S. G., "Requirements engineering: elicitation techniques," M.S. thesis, Department of Technology, Mathematics and Computer Science, University West, Sweden, $2008 . \quad$ http://www.divaportal.org/smash/get/diva2:215169/fulltext01

20. Joseph Elijah , "Survey on Requirement Elicitation Techniques: It's Effect on Software Engineering", International Journal of Innovative Research in Computer and Communication Engineering, Vol. 5, Issue 5, May 2017.http://www.ijircce.com/upload/2017/may/1 SURV EY.pdf

21. Tiruneh1 Theodros and Mishra Manish Kumar, "Analysis and Performance Evaluation of Requirement Elicitation Techniques", International Journal of Computer Sciences and Engineering, VOLUME 6, Issue 4 , April 2018.https://www.ijcseonline.org/pdf paper view.php?p aper_id=1855\&18-IJCSE-03167.pdf

22. Sharma Shreta and Pandey S. K., "Revisiting Requirements Elicitation Techniques", International Journal of Computer Applications (0975 - 8887) Volume 75- No.12, August 2013.https://pdfs.semanticscholar.org/692b/30d03ab7f1f d797327d26d2392008b8e3a93.pdf

23. Khaled Almakadmeh and Hanan Al-Zawahreh, "Procedural Model of Requirements Elicitation Techniques", International Conference on Intelligent Information Processing, Security and Advanced Communication, At Batna, Algeria, November 2015.https://www.researchgate.net/publication/28015436 6_Procedural_Model_of_Requirements_Elicitation_Tech niques
24. Sajjad Umar and Hanif Muhammad Qaisar, "Issues and Challenges of Requirement Elicitation in Large Web Projects", Master Thesis, School of Computing, Blekinge Institute of Technology, Sweden, January 2010.https://www.divaportal.org/smash/get/diva2:830517/FULLTEXT01.pdf

25. Zhang Z., "Effective Requirements Development - A Comparison of Requirements Elicitation techniques", Tampere, Finland, Published in SQM2007.http://citeseerx.ist.psu.edu/viewdoc/download ?doi=10.1.1.135.185\&rep=rep1\&type $=$ pdf

26. Batra Mona and Bhatnagar Dr. Archana Bhatnagar, "An Experimental Survey to Find Application Specific Elicitation Technique", 4th International Conference on "Computing for Sustainable Global Development", 01st 03rd March, 2017 Proceedings of the 11th INDIACom, 2017 New Delhi (INDIA).

27. Arif Mohd. and Sarwar Saoud, "Identification of Requirements using Goal Oriented Requirements Elicitation Process", International Journal of Computer Applications ,Volume $120-$ No.15, June 2015.https://research.ijcaonline.org/volume120/number1 5/pxc3904070.pdf

28. Sadiq M, A Jawed, Asim M, Qureshi A, Suman R, "More on Elicitation of Software requirements and prioritization using AHP", IEEE International Conference on Data Storage and Data Engineering pp 232-236, February 2010, Bangalore, India.

29. Kelly G The psychology of personal constructs, Norton, New York (1955).https://www.researchgate.net/profile/Gabriele_Ch iari2/publication/317064022_George_A_Kelly_and_His Personal_Construct_Theory_iBook/links/5923eceda6fdc c4443fa3cf4/George-A-Kelly-and-His-PersonalConstruct-Theory-iBook.pdf

30. Tiwari Saurabh, Rathore Singh Santosh, and Gupta Atul, "Selecting Requirement Elicitation Techniques for Software Projects", CSI 6th International Conference on Software Engineering, CONSEG 2012

31. Paetsch, F., Eberlein, A. and Maurer, F., "Requirements Engineering and Agile Software Development. Enabling Technologies". pp. 308-313, IEEE, 2003.

32. Anwar Fares and Razali Rozilawati, "A Systematic Stakeholders and Techniques Selection Framework for Software Requirements Elicitations, Journal of Theoretical and Applied Information Technology, Vol.96. No 16, Last Retrieved on 9 June 2019 http://www.jatit.org/volumes/Vol96No16/21Vol96No16. $\underline{\mathrm{pdf}}$ 